\title{
Exploring the Identities of Greek Migrant Young Adults Through Their New Media Use: Combining Public Pedagogy, Participatory Narrative Inquiry, A/r/tography and Heteroglossia
}

Melina Mallos

University of Melbourne

\begin{abstract}
In the 21st century, transnational migration is increasingly commonplace alongside the proliferation of new media. Adolescent migrants are especially well versed in new media, and their interactions allow insights into identity representation and negotiation. We know from current research that a sense of self is likely to be affected and interrupted when migrating to a new country, but we do not know the ways young people with transnational identities, negotiate, shape and are shaped by new media. Using a Participatory Narrative Inquiry approach and arts-based research methods, this research will explore how Greek migrant youths living in Melbourne use new media to communicate and describe their identity. In sharing deeply personal narratives, what do the participants learn about new media's role in their identity formation?
\end{abstract}

Keywords

migrant youth; social media; Greek migrant identity; narrative; 
Public Pedagogy is concerned with aspects of learning in spaces and discourses beyond schools, and the impact of popular culture on everyday life (Sandlin, O’Malley \& Burdick 2011). My research is situated in the field of identity learning for migrants, specifically, the ways media technologies are shaping connection and belonging (Levitt \& Glick-Schiller 2004). For the purposes of this paper, new media will be explored as a form of public pedagogy. I adopt the definition that new media is a 'constellation of media changes, in a move toward more digital, networked, and interactive forms, which together define the horizon of the new' (Ito et al. 2010, p. 10). Today, digital culture has become the means for enacting forms of public pedagogy to engage others and the world around them (Trifonas 2010). This paper aims to add to this body of work by describing how research undertaken using video conferencing with a Greek migrant youth population to explore identity through participatory narrative inquiry, a/r/tography and the conceptual framework of heteroglossia (Bakhtin, 1981/1984).

Scholars have highlighted digital popular cultures as spaces of possible resistance, arguing that these spaces are "an important resource for kids to develop their own cultural identities and sense of social agency" (Giroux 2001, p. 23). My research will add to the body of knowledge considering digital public pedagogies (see Trifonas, 2010; Reid, 2010 \& Freishtat 2010) by exploring the following ideas:

Popular culture and everyday life. Reid (2010, p. 195) stated that, "the emergence of social media alters the cultural conceptions of public and private spaces in a manner that destabilises the conventions that have allowed us to consider a "public pedagogy" separated from formal schooling and other sites of learning". My participants aged $18-24$ years interacted through social media daily.

Informal institutions and public spaces. Institutions of informal schooling environments like the Greek Community Centre on Lonsdale Street, Melbourne can play a pivotal role in bringing together members of the Greek diaspora. Trifonas (2010, p. 179) suggests that digital culture offers up "a shared cultural and public space that requires the negotiation of meaning among the constituent members of a learning community". Communication in digital spaces such as email, video conferencing, and instant messaging has allowed for real time encounters, and enabled new representations of identities to emerge for new migrants living in Melbourne.

Dominant cultural discourses. "Social media platforms have become important sites of public pedagogy, places where we go to learn, and places where we learn indirectly as we come to understand ourselves in relation to others and our culture through social media interactions" (Reid 2010, p. 194). The exploration and choice of identities for my participants, whether through written or spoken language, was dependent in my study on the recipients of their online communities.

\section{Problem}

Researchers have extensively explored the link between migration and identity (Vertovec 2010; Evergeti \& Zontini 2006; Siebers 2017; Erel, Murji \& Nahaboo 2016; Georgakopoulou 2006; Gilmartin \& Migge 2015; Anthias 2009). Though an exciting topic, there is currently only a limited amount of research into how young people with transnational identities negotiate (Leung 2005; Nakamura 2008) and shape their identities through new media practices (Kim 2018). Kim (2018) discovered that "transnational new media provided youths with a multimodal toolbox to communicate and articulate the complexity of their identities" (p. 298). 


\section{Purpose of the Research}

The overall purpose of my research was to explore how Greek migrant youths, aged 18-24 years, living in Melbourne since 2010, used new media to communicate, explore and negotiate their identities.

Central research question and conceptual underpinnings. Specifically, the research question addressed was, 'In what way are the identities and sense of belonging of Greek migrant youths shaped and negotiated within digital public spaces?' To answer this question, I focused on the following conceptual underpinnings:

1. Interaction with 'experts' - i.e. Greek migrant youths who use new media.

2. Artmaking and talking in digital public spaces - participants as co-collaborators in a shared digital "workshop" space of video conferencing.

3. Focusing on language in the participant narratives and artmaking responses - As bilingual young adults, what does the choice of language enable us to express and explore our identities?

4. 'Walking' through digital public spaces - learning and negotiating identities together in a community created through video conferencing.

\section{Research Design: Participatory Narrative Inquiry}

It is through stories that we can see ourselves in different ways and form a new self (McAdams 2001). Participatory narrative inquiry (Kurtz 2014) researchers gather stories to better understand a particular circumstance or providing the space for stories to be told for the first time. Sharing my own migrant experience with the participants made this methodology appropriate and authentic, especially as I was using the medium of new media (see Figure 1).
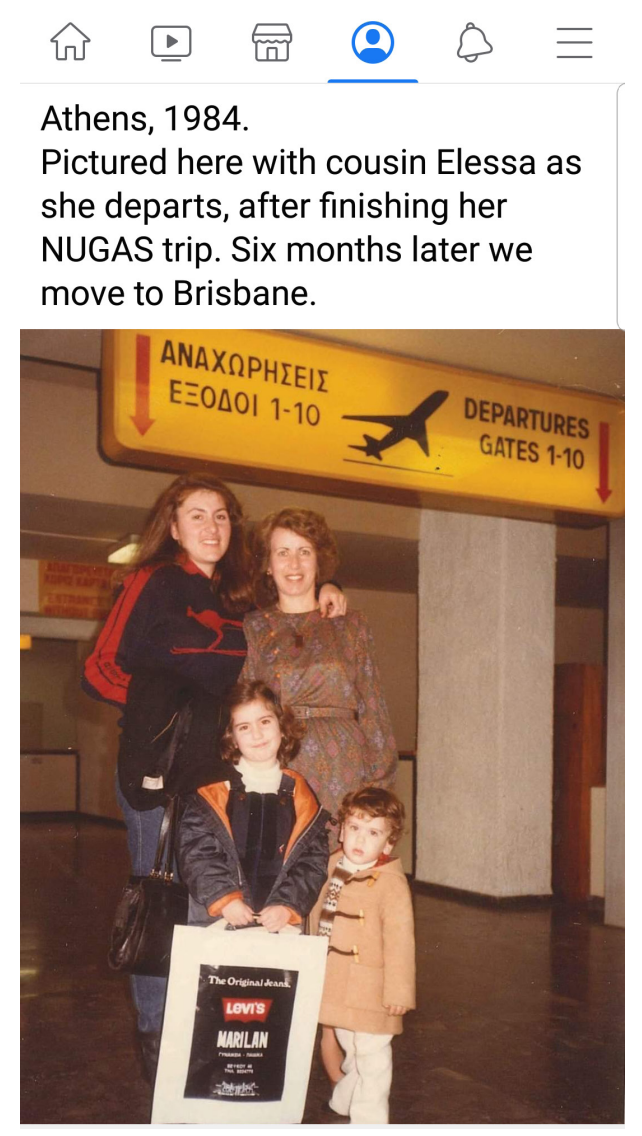

Figure 1: My Migration Beginning Shared via Facebook. 
The scope of my research aligned with the three essential phases for any PNI research: (1) collection, (2) sensemaking, and (3) return. Through a series of participatory arts workshops, my research design aimed to:

1. Document new public pedagogy media practices of the young adult Greek migrant population in Melbourne.

2. Record participant reflections on their identities through their new media use.

3. Create multimodal digital narratives and portraits to explore and communicate these identities.

4. Enable participants to collectively identify and respond to themes from the data collected.

5. Choose ways to disseminate key findings to the Greek community in Melbourne to deal with issues migrant youths face when migrating to Australia.

Collection. In the Collection phase, participants explored and negotiated meaning through the stories exchanged (Kurtz 2014) in a digital public space. Narratives were collected in visual, verbal and written forms. The data collection methods used for each PNI phase are listed in Table 1.

\begin{tabular}{|c|c|c|}
\hline PNI workshop phase & A/r/tography & Heteroglossia \\
\hline Collection & $\begin{array}{l}\text { - Instagram portraits } \\
\text { - Journaling } \\
\text { - Digital narratives }\end{array}$ & $\begin{array}{l}\text { - Peer interviews (pairs) } \\
\text { - Social media screenshots } \\
\text { - Whole group discussions }\end{array}$ \\
\hline Sensemaking & $\begin{array}{l}\text { Sharing an exploration of } \\
\text { the data to creatively arrive } \\
\text { at a new understanding }\end{array}$ & $\begin{array}{l}\text { Collective and individual } \\
\text { identities }\end{array}$ \\
\hline Return & A survival guide for new Greek migrants \\
\hline & to Australia on how to use new media. \\
\hline
\end{tabular}

Table 1: Structure of the Participatory Workshops.

Sensemaking. Sensemaking involved the group of participants coming together to explore the gathered narratives during the participatory workshops and explored all data within the digital public space of Cloudstor. Kurtz (2014) states that sensemaking needs to happen with the participants in a group setting. In my study, this was undertaken via videoconferencing.

Return. The Return phase allowed participants to use their newly found information and understanding to bring about change, and increased awareness of the impact or issues pertaining to their use of new media and their identities. The participants created a survival guide for new migrant youths to Melbourne on how to navigate their use of new media.

\section{Why is $\mathrm{A} / \mathrm{r} /$ tography Important for this Study?}

With a/r/tography I could position myself as a participant in a digital space, as both researcher and facilitator. A/r/tography is an "evocative" (Springgay et al. 2005, p. 903) practice that includes the integration of identity, reflection and autobiography into the role of artist, teacher and researcher (Springgay et al. 2005). As Coleman (2017) suggested, a/r/tography is an embodied praxis that allows her to look, read, practice, write and make through the 
lenses of an intertwined, woven and entangled self of assemblage of selves. My experiences as a Greek migrant in Australia were relevant to this research and shaped its design as a form of public pedagogy. As Bott (2010) noted, "central to maintaining reflexivity is the need for researchers to constantly locate and relocate themselves within their work" (p. 160). My Greek background offered cultural insights when reflecting on the taken-for-granted roles of culture (both Greek culture and new media) as I interpreted the participants' narratives. Due to my languages, Greek background, and experiences with new media, I was more capable of developing an "empathetic understanding" (Holloway \& Wheeler 2002, p. 13). For Christou (2006), being bilingual was a necessary advantage with her participants, second-generation Greek Americans living in Greece: "Coming from the same background, speaking the same language(s), and having the same concerns and experiences were instrumental in gaining the participants' confidence and dedication to the study" (Christou 2006, p. 27). I enacted the role of $\mathrm{a} / \mathrm{r} / \mathrm{tographer}$ in the three following ways, to revisit my own identities and sense of belonging alongside the participants:

In-between spaces. The a/r/tographer is interested in the interstitial spaces of known that lie between, the liminal amidst outsider/insider or artist, researcher, teacher, and writer, and "with each new exploration of in-between public spaces, she is given new insights and encouraged to re-organise one's identity again and again” (Winters, Belliveau \& Sherritt-Fleming 2009, p. 7). The participants and myself negotiated our identities through artmaking within a digital public space: "Works of art are, like everything else that really exists, analysable as both form and matter, but qua existing things they exhibit an identity of the two; what the matter has become is this shaped thing" (Bakhtin 1997, p. 17). As new media is a communication tool reflective of the current times, we created digital narratives and Instagram portraits (see Figure 2):

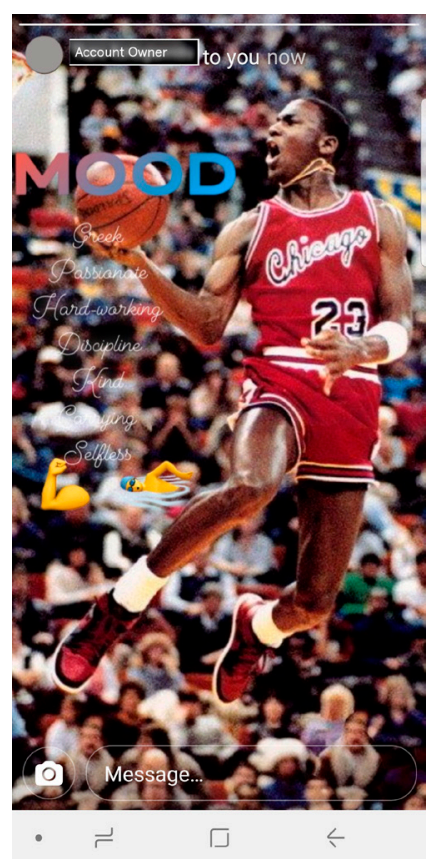

Figure 2: Participant Instagram Portrait.

Multiple understandings. With each new vantage point, the a/r/tographer gains multiple understandings, and Springgay and Irwin (2007), and others (e.g., Bakhtin 1999; Sumara 2002; Coleman 2017) suggest that identity is continually constituted and negotiated through lived encounters with others. So, through sharing in a digital public space, the 
participants gained more understandings and insights about his or her own identity including the contexts that place them within that particular identity than they would have on their own. This was expressed by participant Costas: "New media does not have much of an impact on who I am as a person but more so it allows me to express myself through a different perspective; it makes me feel like I have multiple ways of expressing myself".

Ongoing process (return). Reflective spaces are necessary for $\mathrm{a} / \mathrm{r} /$ tography. Resting spaces give learners opportunities to re-organise what they know. "Data is layered and interwoven in complex and original ways so that questions and answers inform each other; data are constructed, interrupted, de-constructed, and re-constructed" (Winters, Belliveau \& Sherritt-Fleming 2009, p. 8). These processes were used by my participants in sharing their last photo taken in Greece and shared via social media. Sharing for understanding, making sense of experiences "as an ongoing exchange between Self and Other, and between texts and images” (Springgay, Irwin \& Kind 2005, p. 13) can be discerned through Figure 3.

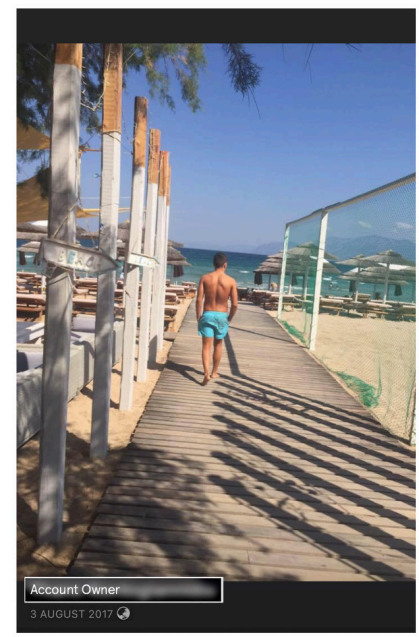

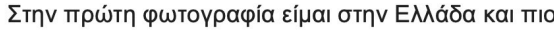

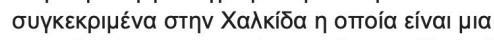

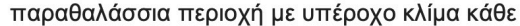

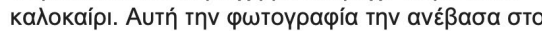

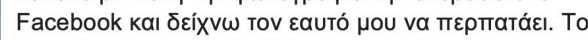

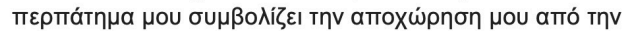

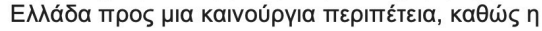

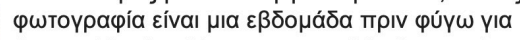

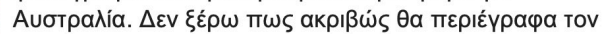

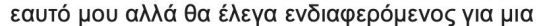
kaıvoúpyıa apxń.

In this photograph I am in Greece, specifically, Halkida, which is a coastal area with fantastic weather every summer. I uploaded this photograph to Facebook and show myself walking. My walk is symbolic my farewell from Greece toward new adventures as well as it being one week before I was to leave for Australia. I don't know exactly how I'd describe myself but I'd say, interested in a new beginning. (Costas)

Figure 3: Participant Photograph shared via Social Media and Reflection.

\section{Conceptual Framework: Why Heteroglossia?}

Researchers have highlighted and "recognised the importance of the many voices of Bakhtin's dialogism in the generation of social knowledge" (Zappen 1996, p. 8). In other words, through many voices human beings form understanding through dialogue, and come to understand ourselves through our interactions positioned within, and inseparable from, a community, a history, a place. My research explored how dialogue generated within a digital public space may allow shifts in identities to take place. The task was "to find one's own voice and to orient it among other voices, to combine it with some and to oppose it to others, to separate one's voice from another voice with which it has inseparably merged" (Stone 1988, p. 9). Speech and complex cultural discourse in all our genres (novels, scientific descriptions, art works, philosophical arguments, for example) are inherently heteroglossic (mixed through and with another's speech, many others' words, and appropriated expressions) and are polyphonic ('many-voiced', incorporating many voices, styles, references, and assumptions not a speaker's 'own') (Bakhtin 1986 in Irvine 2004), recognition of which has led to increased interest in this area. Heteroglossia was clearly in my data collected through the participants' language choices when communicating through new media, such as text messaging and social media comments and posts. Considering the widespread use of new media, Bakhtin's 
(1984) conceptual idea of heteroglossia can be better understood in terms of its impact on expression, perception, and communication in digital public spaces. Bakhtin's 'I-for-myself', 'I-for-the-other', and 'the-other-for-me' (1981; 1986). Without the other, the self cannot exist (Bakhtin 1986). "I-for-myself' is restricted, 'to a partial 'inside' perspective, which can only be transcended through an external vantage point" (Erdinast-Vulcan 2008, p. 4). Our identities reflect back to us how we are viewed by others, with dialogue being one of the ways that our self-awareness is raised.

\section{Participatory Narrative Inquiry, A/r/tography and Heteroglossia}

Participation in the digital public space allows for additional understandings to be gained about Greek migrant youths and their identities. Identities communicated and constructed within the digital public space of new media, were viewed in this study through the intersection of participatory narrative inquiry, a/r/tography and heteroglossia (see Figure 4). A/r/ tography offered both me, and the Greek migrant youths, as co-collaborators, an agency to exchange personal perspectives in a digital space connected through shared experiences. Contributions "co-emerged simultaneously within and through time and space" (Bickel, Springgay, Beer, Irwin \& Xiong 2010, p. 88). My data collection through video conferencing, allowed for participants to explore their reflections, social media accounts, digital narratives, and Instagram portraits, and consider as relevant data as users of these popular culture tools of communication.

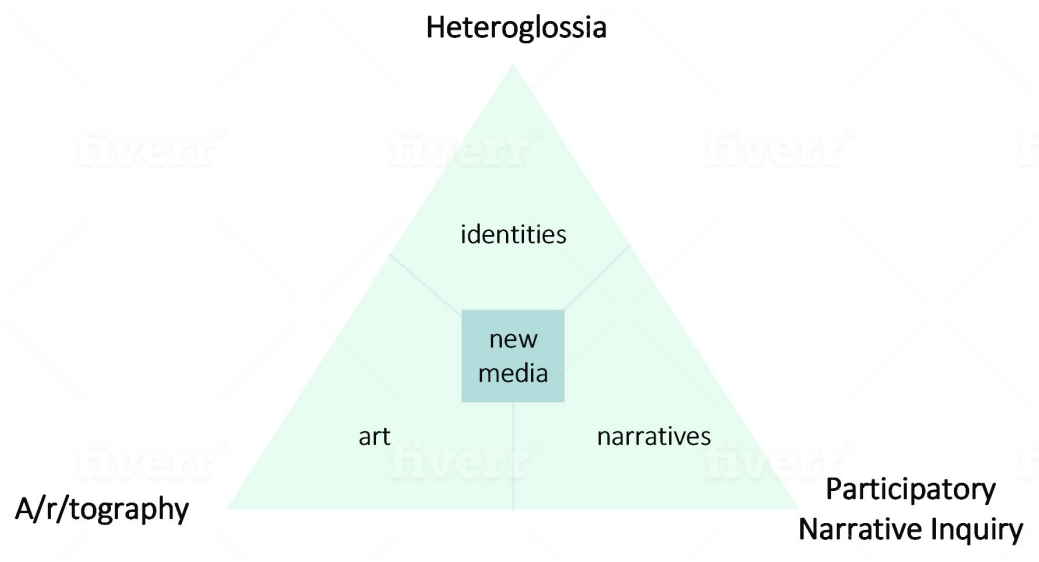

Figure 4: The Intersection of PNI, A/r/tography and Heteroglossia.

In keeping with an a/r/tographical approach, Bakhtin (1984) sees life as part of a process of experiencing the world with others. Some limitations may exist when relating Bakhtin's theories $(1981 / 1984)$ to new media, largely because of the technological revolution that has occurred since this theory was proposed, but they speak to $\mathrm{a} / \mathrm{r} /$ tography in the sense that new media has allowed for new art (writing style, artistic expression) to be communicated using different mediums and acknowledges language and meaning as both adaptive and ever-changing. Bakhtin's (1984) conceptual idea of heteroglossia, however, can be better understood in terms of how interaction through new media impacts expression, perception, identities and communication. Bakhtin's theories (1981/1984) on the utterance/word (including linguistic composition - phonetics, vocabulary, morphology) seem to be an example of transformation to the present-day style of communication through new media. In addition to Bakhtin's (1981/1984) theories of narratives communicated through text, Rosunee (2012) asserts that the arts-based practice can be used to understand and conceptualise the 'self' and the 'other' - essentially stating that the images used in narrative inquiry are superior in gaining an understanding of the 'self' and 'other' - using an a/r/trophic approach. 
Visual representations and narratives merge in understanding, mediating and recognising messages, meanings and significances through them. Identities are continually shaped by the digital space we gathered, while at the very same time, through my participation as $\mathrm{a} / \mathrm{r} /$ tographer, I shaped the identities of the youths as co-collaborators.

\section{Conclusion}

This article added to the argument of digital space as a public pedagogy. My findings explored this notion by interrogating an exploration of Greek migrant young adults' identities and new media through a synthesis of participatory narrative inquiry (PNI), a/r/tography, and Bakhtin's concept of heteroglossia (1981/1984). The paper described the theoretical backdrop of public pedagogy to my study, specifically, popular culture and everyday life, informal institutions and public spaces, and dominant cultural discourses. The participatory arts and narrative design helped to highlight the different identities that Greek migrant youths inhabit through the affordances of new media. As an a/r/tographer, bringing together the youth participants' articulations, discussions and artmaking, and directing these to my own sense of self and belonging will be a unique contribution in terms of exploring how participants' identities may shift through their interaction with others via video conferencing. 


\section{References}

Anthias, F 2009, 'Translocational belonging, identity and generation: Questions and problems in migration and ethnic studies', Finnish Journal of Ethnicity and Migration, vol.4, no. 1, pp. 6-15.

Bakhtin, M M 1981, The dialogic imagination: four essays, University of Texas Press, Austin, Texas.

Bakhtin, M M 1984, Rabelais and his World, H. Iswolsky, Indiana University Press, Bloomington, Indiana.

Bakhtin, M M 1986, Speech genres and other late essays, University of Texas Press, Austin, Texas.

Bakhtin, M M 1997, Problems of Dostoevsky's poetics, University of Minnesota Press, Minneapolis, Minnesota.

Bakhtin, M M 1999, 'The problem of speech genres', The discourse reader, Routledge, New York.

Bickel, B, Springgay, S, Beer, R, Irwin, R Grauer, K, \& Xiong, G 2010, 'A/r/tographic collaboration as radical relatedness', International Journal of Qualitative Methods, vol.10, no. 1 , pp. 86-102.

Bott, E 2010, 'Favourites and others: Reflexivity and the shaping of subjectivities and data in qualitative research', Qualitative Research, vol.10, no. 2, pp. 159-173.

Christou, A 2006, Narratives of place, culture and identity: Second-generation GreekAmericans return 'home', Amsterdam University Press, Amsterdam.

Coleman, K S 2017, An alr/tist in wonderland: Exploring identity, creativity and digital portfolios as a/r/tographer (Doctoral dissertation).

Del Vecchio, D, Toomey, N, \& Tuck, E 2017, 'Placing photovoice: Participatory action research with undocumented migrant youth in the Hudson Valley', Critical Questions in Education, vol.8, no. 4, pp. 358-376.

Elbaz-Luwisch, F 2005, Storytelling and possibility: The arts and practices of storytelling, Information Age Publishing, Greenwich, Connecticut.

Elbaz-Luwisch, F 2002, 'Writing as inquiry: Storying the teaching self in writing workshops', Curriculum Inquiry, vol.32, no. 4, pp. 403-428.

Erdinast-Vulcan, D 2010, 'Borderline subjectivity: The futurity of the present in Bakhtin's work', Partial Answers: Journal of Literature and the History of Ideas, vol.8, no. 1, pp. 169-183. Baltimore, Maryland: Johns Hopkins University Press.

Erel, U, Murji, K \& Nahaboo, Z 2016, 'Understanding the contemporary race-migration nexus', Ethnic and Racial Studies, vol.39, no. 8, pp. 1339-1360.

Evergeti, V \& Zontini, E 2006, 'Introduction: Some critical reflections on social capital, migration and transnational families', Ethnic and Racial Studies, vol.29, no. 6, pp. 1025-1039.

Freistat, R L 2010, 'Constructing community, disciplining dissent: The public pedagogy of facebook as a social movement' in J A Sandlin, B D Schultz \& J Burdick (eds), Handbook of public pedagogy: education and learning beyond schooling, Routledge, New York, pp. 201-213. 
Georgakopoulou, A 2006, 'Thinking big with small stories in narrative and identity analysis', Narrative Inquiry, vol.16, no. 1, pp. 122-130.

Gilmartin, M \& Migge, B 2015, 'Home stories: Immigrant narratives of place and identity in contemporary Ireland', Journal of Cultural Geography, vol.32, no. 1, pp. 83-101.

Giroux, H A 2001, Stealing innocence: Corporate culture's war on children, Palgrave Macmillan, New York.

Hampton, K N, Lee, C\& Her, E J 2011, 'How new media affords network diversity: Direct and mediated access to social capital through participation in local social settings', New Media \& Society, vol.13, no. 7, pp. 1031-1049.

Holloway, I \& Wheeler, S 2002, Qualitative research in nursing, Blackwell Science, Oxford: Connecticut.

Irvine, M 2004, 'Bakhtin: Main theories', Georgetown University viewed 20 June 2020, <http://faculty.georgetown.edu/irvinem/theory/Bakhtin-MainTheory.html>.

Ito, M, Baumer, S, Bittanti, M., Boyd, D, Cody, R, Herr-Stephenson, B, Horst, H A., Lange, P G, Mahendran, D, Martínez, K Z, Pascoe, C J, Perkel, D, Robinson, L, Sims, C, \& Tripp, L 2010, Hanging out, messing around, and geeking out. Cambridge, Massachusetts: The MIT Press.

Kim, S 2018, 'Migrant youth identity work in transnational new mediascape: A case study of what it means to be Korean for migrant adolescent', Journal of Asian Pacific Communication, vol.28, no. 2, pp. 281-302.

Kurtz, C 2014, Working with stories in your community or organization: Participatory narrative inquiry, Kurtz-Fernhout Publishing, New York.

Leung, C 2005, 'Convivial communication: Recontextualizing communicative competence', International Journal of Applied Linguistics, vol.15, no. 1, pp. 119-144.

Levitt, P, \& Glick-Schiller, N 2004, 'Conceptualizing simultaneity: A transnational social field perspective on society', The International Migration Review, vol.38, no. 3, pp. 1002-1039.

McAdams, P D 2001, 'The psychology of life stories', Review of General Psychology, vol.5, no. 2 , pp. 100-122.

Mullen, C 2003, 'Guest editor's introduction: a self-fashioned gallery of aesthetic practice', Qualitative Inquiry, vol.9, no. 2, pp. 165-181.

Nakamura, L 2008, Digitizing race: visual cultures of the internet, University of Minneapolis, Minneapolis, Minnesota.

Pinar, W F 1975, The Method of 'Currere'. Paper presented at the Annual Meeting of the American Research Association. Washington, D.C. Retrieved from https://files.eric. ed.gov/fulltext/ED104766.pdf

Reid, A 2010, 'Social media, public pedagogy, and the end of private learning', in J A Sandlin, B D Schultz \& J Burdick (eds), Handbook of public pedagogy: education and learning beyond schooling, Routledge, New York, pp. 194-200.

Rosunee, N D 2012, 'Unlocking and negotiating meanings through narratives and visual representations', International Journal of Learning, vol.18, no. 8, pp. 33-49. 
Rule, P 2011, 'Bakhtin and Freire: Dialogue, dialectic and boundary learning', Educational Philosophy and Theory, vol.43, no. 9, pp. 924-942.

Sandlin, J A, O’Malley, M P. \& Burdick, J 2011 'Mapping the Complexity of Public Pedagogy Scholarship: 1894-2010', Review of Educational Research, vol.81, no. 3, pp. $338-375$.

Siebers, H 2017, "Race' versus 'ethnicity'? Critical race essentialism and the exclusion and oppression of migrants in the Netherlands', Ethnic and Racial Studies, vol.40, no. 3, pp. 369-387.

Springgay, S, \& Irwin, R L 2007, 'A/r/tography as practice-based research'. In M. Cahnmann \& R. Siegesmund (Eds.), Arts-based research in education: foundations for practice (pp. 71-77). New York: Routledge.

Springgay, S, Irwin, R L, \& Kind, S W 2005, 'A/r/tography as living inquiry through art and text', Qualitative Inquiry, vol.11, no. 6, pp. 897-912.

Stone, D D 1988, 'Meredith and Bakhtin: polyphony and bildung', Studies in English Literature, 1500-1900, vol.28, no. 4, pp. 693-712.

Sumara, D 2002, Why reading literature in school still matters: Imagination, interpretation, and insight, Lawrence Erlbaum Associates Inc, Mahwah: New Jersey.

Trifonas, P P 2010, 'Digital literacy and public pedagogy: Notes on the digital game as a form of literacy and learning', in J A Sandlin, B D Schultz \& J Burdick (eds), Handbook of public pedagogy: education and learning beyond schooling, Routledge, New York, pp. 179-184.

Vertovec, S 2001, 'Transnationalism and identity', Journal of Ethnic and Migration Studies, vol.27, no. 4, pp. 573-582.

Winters, K L, Belliveau, G, \& Sherritt-Fleming, L 2009, 'Shifting identities, literacy, and a/r/tography: exploring an educational theatre company', Language and Literacy, vol.11, no. 1, pp. 1-19.

Zappen, J P 1996, 'Bakhtin's socrates', Rhetoric Review, vol.15, no. 1, pp. 66-83. 